\title{
CARLOS ROBERTO ANTUNES DOS SANTOS E A HISTÓRIA DA ALIMENTAÇÃO NO PARANÁ
}

\author{
Carlos Roberto Antunes dos Santos and the history of \\ food in the Paraná
}

\author{
Maria Cecília Barreto Amorim Pilla* \\ Cilene da Silva Gomes Ribeiro*
}

\begin{abstract}
RESUMO
O objetivo deste artigo é trazer para discussão o clássico História da alimentação no Paraná, de Carlos Roberto Antunes dos Santos, publicado pela primeira vez em 1995, propiciando a reflexão sobre os movimentos econômicos, sociais e políticos ocorridos no século XIX, na Província do Paraná, a partir da produção e do acesso aos alimentos e revelando as permanências que se verificam na produção e no consumo balizado pelo jogo do mercado capitalista. Atualmente, muito do que foi registrado como pertencente aos movimentos do século XIX se replica, seja nas relações de produção, distribuição, seja no consumo dos alimentos, evidenciando-se a atualidade e a importância da referida obra, que aborda temas persistentes e recorrentes no Brasil. Dada uma série de dilemas atuais, incluindo a insegurança alimentar, a falta de sustentabilidade ecológica e a necessidade de se garantir o direito humano à alimentação adequada e saudável, é pungente retornarmos à análise pretendida pelo autor, a partir da trilogia por ele defendida - escassez, carestia e qualidade.
\end{abstract}

Palavras-chave: história da alimentação no Paraná; Carlos Roberto Antunes dos Santos; consumo alimentar

\begin{abstract}
The objective of this paper is to bring to the discussion the classic História da Alimentação no Paraná, by Carlos Roberto Antunes dos Santos, first published in 1995 , promoting reflection on economic, social and political movements in the 19th century in
\end{abstract}

\footnotetext{
* Doutora em História pela Universidade Federal do Paraná (2004). Atualmente é professor Adjunto III da Pontifícia Universidade Católica do Paraná. E-mail: ceciliapilla@gmail.com

** Doutora em Historia pela UFPR. Atualmente professora adjunta da Pontifícia Universidade Católica do Paraná. E-mail: cilenex@hotmail.com
} 
the Province of Paraná, from the production and access to food and revealing the permanences that occur in the production and consumption marked by the game of the capitalist market. Nowadays, much of what was registered as belonging to the movements of the nineteenth century is replicated, not only in the relations of production, distribution, but also in the consumption of food, evidencing the relevance and importance of this work, which addresses persistent and recurring themes in Brazil. Given a number of current dilemmas, including food insecurity, lack of ecological sustainability and the need to ensure the human right to adequate and healthy food is poignant returning to the analysis by the author, from the trilogy he advocated - shortage, dearness and quality.

Keywords: history of food in the Paraná; Carlos Antunes dos Santos; food consumption

$* * *$

1. Carlos Roberto Antunes dos Santos, historiador falecido em 2013, nasceu em Porto Alegre-RS tendo sua formação acadêmica iniciada com a Graduação em História pela Universidade Federal do Paraná, onde também obteve o seu título de Mestre, em setembro de 1974, com a Dissertação "Preços e Profissões de Escravos no Paraná 1860/1887". Mais tarde, ainda nos anos 1970, doutorou-se pela Universidade de Paris X- Nanterre/França, com a Tese intitulada "Economia e Sociedade Escravista no Paraná". Entre 1984 a 1986 realizou programa de Pós-Doutorado na École des Hautes Études d'Amérique Latine, na Universidade de Paris III/França, concluindo o referido programa com o trabalho intitulado "História Econômica do Brasil no contexto latino-americano". Em 1992, através de concurso de provas e títulos alcançou a categoria de Prof. Titular do DEHIS/UFPR, com a tese "Alimentar o Paraná Província".

Como se vê, Santos desenvolveu estudos sobre o Paraná desde em suas primeiras pesquisas. A partir da análise de aspectos políticos, sociais e econômicos do estado nos séculos XVIII e XIX, acabou trazendo à tona uma história até então pouco retratada e valorizada no âmbito das pesquisas historiográficas: a da alimentação. 
Sua grande tese é que o alimento - sua produção, distribuição e consumo - interferiram de forma direta na formação do atual Estado do Paraná.

Quando Santos iniciou suas pesquisas no âmbito da alimentação, não era comum entre os historiadores considerar o alimento como categoria histórica. A comida e os gêneros alimentícios, em geral, apareciam como aspectos de estudos mais amplos sobre a sociedade rural e as estruturas agrícolas. Quando este estudioso escreveu sua primeira obra sobre o assunto, revelou um aspecto importante da formação do Paraná, de experiência assentada no campo, e ainda investiu em uma temática fundamental para a compreensão da vida de todos os seres humanos.

Com seus estudos analisou de que modos a escassez e a carestia de alimentos afetaram diretamente a estrutura de produção agroalimentar da Província do Paraná no final do século XVIII e na primeira metade do século XIX, retardando sua consolidação como uma parte independente da federação. Ainda, analisou como a disponibilidade de alimentos foi condicionante na formação dos hábitos alimentares da população local e como tais acesso interferiram nos costumes.

O objetivo do presente artigo é realizar uma leitura atualizada do clássico História da alimentação no Paraná, publicado pela primeira vez em 1995. Para tanto, serão realizadas duas etapas de reflexão. Num primeiro momento, pretende-se descrever o panorama feito pelo autor da produção de alimentos no Paraná no final do século XVIII e na primeira metade do século XIX, procurando identificar as principais características da penúria e da carestia dos alimentos, bem como a atuação das políticas nacionais e regionais nos processos de colonização e emancipação da região. Em um segundo momento, realiza-se uma síntese da estrutura agroalimentar na Província do Paraná, com foco nos principais alimentos da região, de acordo com Santos ${ }^{1}$ (2007): o feijão, o milho, a mandioca, o arroz, a carne, o trigo e a erva-mate. Em um terceiro momento, busca-se na principal tese do autor - a trilogia escassez, carestia e qualidade dos

1 SANTOS, Carlos Roberto Antunes dos. História da alimentação no Paraná. Curitiba: Juruá, 2007. Para esse artigo tomamos a edição realizada pela Editora Juruá do ano de 2007. 
alimentos - uma relação com alguns traços da situação alimentar atual, partindo-se do pressuposto de que o estudo da história contribui para propor elementos e algumas respostas aos problemas contemporâneos, dentre eles, as questões alimentares.

$* * *$

2. Em História da alimentação no Paraná, Santos ${ }^{2}$ evidenciou que é por meio da análise das crises de produção de alimentos e de abastecimento que se pode chegar a conhecer a história das tensões, dos conflitos e da própria estrutura de produção alimentar de uma sociedade - sendo a história do abastecimento "(...) uma história que se regionaliza, que foge do nacional, que se particulariza, mesmo que suas coordenadas estejam presas a determinações de sistemas maiores".

Ao realizar suas pesquisas, Santos (2007) explicitou que os estudos sobre o campesinato no Brasil, com mão de obra nacional ou estrangeira, revelaram-se sob um permanente aspecto de marginalidade, não tendo um papel de destaque na história brasileira. Tal população era vista como fixada no interior, dependente, rústica e que produzia apenas o suficiente para seu sustento. Pouco se evidenciou, à época, sobre suas características, com destaque para suas produções, que integravam o circuito do comércio e dos mercados urbanos; raramente se mencionava que a pequena produção se apresentava como um segmento social inserido no processo do capital comercial, ao gerar excedentes que eram apropriados por agentes econômicos. Por tais observações é que a obra de Santos continua viva e atual, podendo ser utilizada por todos os pesquisadores que estudam a produção de alimentos e a soberania alimentar. Sem o alimento de subsistência, sem o campesinato, não há crescimento, vida e saúde para o ser humano e a natureza.

2 SANTOS, op.cit.,p.18. 
Para a elaboração da obra em análise, $\operatorname{Santos}^{3}$ partiu de algumas premissas: 1 - de que a partir da segunda metade do século XIX estava surgindo na Província do Paraná um projeto que visava gerar modernidade e desenvolvimento à região, fazendo com que muitas medidas, tal como a formação de uma estrutura agroalimentar, fossem ensaiadas; 2 - de que o sistema produtivo provincial deveria ser definido a partir da dinâmica de produção agroalimentar, do estabelecimento de políticas de abastecimento e da formação e regulamentação do mercado de alimentos; e, 3 - de que a expansão do setor de exportação de alimentos havia criado uma série de efeitos de retorno, impactando diretamente no setor de subsistência.

Como método de investigação, realizou levantamentos e arrolamento de fontes históricas para captação de dados quantitativos e qualitativos sobre a questão agroalimentar e suas dimensões, a partir dos acervos do: Instituto de Terras e Colonização do Paraná (ITCF); cartórios de registros do Cível, comércio e anexos; Sessão Paranaense da Biblioteca Pública do Paraná; Arquivo Público de Curitiba; Arquivo da Câmara Municipal de Curitiba. As fontes utilizadas nas pesquisas que geraram a obra foram: relatórios dos presidentes de Província; correspondência dos Presidentes de Província; boletins do Arquivo Público Municipal; posturas municipais; fontes de imprensa; e, anuário estatístico.

Para Santos $^{4}$, foram as políticas de produção e de abastecimento estabelecidas na Província do Paraná, especialmente a partir do século XIX, que deram origem ao atual estágio de desenvolvimento. À época, havia o desejo de atingir dois grandes objetivos, principalmente a partir do governo de Lamenha Lins: a emancipação dos escravos e a implantação de um novo sistema de colonização e imigração, ambas embasadas e sustentadas pela produção e distribuição de alimentos. $\mathrm{O}$ projeto de modernidade e desenvolvimento implementado na Província do Paraná após a promulgação da Lei de Terras de 1850 estava diretamente relacionado à colonização e ao abastecimento pelo estímulo à vinda de imigrantes europeus e o aumento da produção de alimentos básicos. Lamenha 
Lins defendia um projeto que isso permitiria maior circulação de gêneros alimentícios diretamente das unidades de produção para as unidades de consumo, gerando uma dinamização do mercado interno, caracterizando sistemas produtivos regionais.

Santos ${ }^{5}$ explicitou em sua obra que o alimento, sua produção, distribuição e consumo, são as bases do crescimento civilizatório. Sem alimento e sem comida não há sociedade, não há desenvolvimento e crescimento e, portanto, desde os primórdios, o controle de toda a cadeia logística, que vai desde a produção até o consumo de insumos, determina quem tem o poder, quem comanda e quem é comandado. Os interesses mercantis europeus definiram as formas de ocupação, produção e exploração do território brasileiro ao longo de todo o processo de colonização. Foram as atividades exportadoras que estabeleceram o que, quando e como se produziam as matérias-primas, fossem elas para a exportação ou para consumo interno, implicando o estabelecimento de grandes unidades de produção e interesses comerciais.

Com o desenvolvimento da exploração do ouro em Minas Gerais e a concentração de esforços do mercado internacional neste tipo de comércio, algumas outras regiões do país, desprovidas de tal riqueza, passaram a ser percebidas e a contribuir em âmbito nacional. É o caso da pecuária sulina, que passou a ter grande importância na alimentação da população mineradora e do restante do país, auxiliando na articulação das diferentes regiões do sul. O Estado do Paraná, por exemplo, a partir da segunda metade do século XVIII ainda não havia estabelecido nenhuma estrutura produtora de alimentos voltada a suprir as necessidades da sua população porque mantinha como base de sua economia a criação e o comércio de gado, que era levado para os mercados de Sorocaba e constituía parte da exportação sulina. Neste período, um terço da população escrava lidava diretamente com o gado e o restante atuava nas demais atividades das fazendas, que constituíam um conjunto econômico e social integrado e quase autossuficiente, “(...) com a produção de 
alimentos que consistiam basicamente em carne de porco, milho, feijão, mandioca e arroz" ${ }^{\prime 6}$.

Além dos alimentos produzidos na região como o arroz, o feijão e o milho, a farinha de mandioca e o peixe figuravam entre as maiores riquezas do litoral do Paraná, sendo que grande parte do que se produzia era consumida na própria região. De acordo com Santos ${ }^{7}$, a economia da Vila de Curitiba do final do século XVIII estava centrada na produção de bens de consumo destinados, principalmente, aos próprios habitantes, destacando-se a produção de milho, feijão, farinha de mandioca e trigo. É importante citar que esta combinação de alimentos essenciais também fazia parte da alimentação de boa parte do Brasil. Graham, por exemplo, em pesquisas relacionadas com a alimentação em Salvador, cita o arroz, o feijão, o milho e a farinha de mandioca como os alimentos de maior consumo da população entre o século XVIII e XIX ${ }^{8}$.

Em suma, o Paraná do século XVIII se articulou em dois espaços econômicos não-integrados: a área da economia pecuária, nos Campos Gerais, pela criação e transporte do gado e pelo tropeirismo; e, as áreas onde prevaleceram os padrões específicos de economia de subsistência, nas pequenas vilas do planalto e do litoral, que tinham o ritmo lento de produção como modelo instituído e marcante.

No início do século XIX, o setor de subsistência paranaense era bastante limitado, com ínfimo crescimento, gerando a necessidade, inclusive, de importação de produtos essenciais. Além da economia de subsistência ser pouco expressiva por seus métodos de produção, foi neste mesmo período que se evidenciou no Paraná o desenvolvimento da economia de exportação, que tratou de reduzir ainda mais a produção de alimentos para o consumo interno. Desta modalidade faziam parte a economia do mate, que monopolizou praticamente todas as atividades do litoral e do primeiro planalto, e a economia da pecuária, determinante para a ocupação do primeiro e segundo planaltos do Paraná. Estimuladas, respectivamente, pelo comércio com os países do rio da Prata e com as Minas Gerais, essas

8 GRAHAM, Richard. Alimentar a cidade: das vendedoras de rua à reforma liberal (Salvador, 1780 - 1860). São Paulo: Companhia das Letras, 2013. p.147. 
economias foram gerando cada vez mais desequilíbrio entre os setores comerciais e de subsistência, a ponto de gerar uma grave crise de abastecimento na região. Insumos como açúcar, trigo, carnes e toucinho, sal, bebida, tecidos, entre outros produtos agroalimentares e artigos de primeira necessidade, eram escassos e necessitavam ser importados de outras regiões, gerando um déficit entre o que se exportava e o que se importava. Sem tecnologias para a produção agrícola, sem sistemas viários de integração de diferentes regiões que facilitassem o comércio, sem apoios financeiros à pequena produção e com a euforia gerada pela economia do mate e do gado desfocando os interesses da produção agrícola de consumo e gerando seu abandono, os agricultores acabaram por se limitar a produzir apenas o suficiente para o sustento de suas famílias, escasseando, assim, o abastecimento da população.

Curitiba, mesmo sendo um centro administrativo importante na região, e Paranaguá, que propiciava comunicação garantida com o litoral atlântico e possibilidades de escoamento da produção, não possuíam capacidade produtiva e de consumo para atender sequer suas populações, sendo as produções de gêneros alimentícios extremamente precárias. Nas primeiras décadas do século XIX, os mercados de Curitiba e Paranaguá comercializavam os produtos de subsistência básicos à população - milho, feijão, charque, toucinho ou os importados, tais como o açúcar, sal, vinho, vinagre, gado e aguardente - e muitas medidas legais tiveram que ser instituídas no intuito de se combater a escassez e a carestia, a especulação de preços e abusos.

O mate, a partir da segunda década do século XIX, passou a ser o grande foco de produção e exportação do Paraná, situação que se manteve durante quase todo século XIX. Desde o início da década de 1840, o Paraná aumentou de forma considerável sua produção de erva-mate, fazendo com que a atividade ervateira passasse a monopolizar capitais e mão de obra livre e escrava, fato que só se modificou quando as províncias de Santa Catarina e Rio Grande do Sul passaram a produzir erva-mate de melhor qualidade, afetando a produção e a exportação do produto pelo Paraná. O mate, de qualquer forma, tornou-se o “(...) produto fundamental para a integração da 
economia paranaense às rotas da economia brasileira e da EconomiaMundo" e fez prosperar produtores e comerciantes, integrando-os de forma definitiva às rotas do capitalismo. Em contrapartida, a agricultura se manteve reduzida às "(...) pobres lavouras de cana e arroz, no litoral, que movimentavam pequenos engenhos. Por sua vez, no planalto curitibano, apenas escassas plantações de milho. Tudo, porém, em pequena escala" 10 , o que gerava preocupações, já que não havia alimentos suficientes para o consumo da população e para seu crescimento.

Depender de importações de insumos de primeira necessidade era um dos males da concentração de esforços na produção da erva-mate e fazia com que os gêneros alimentícios custassem muito à população. Percebe-se já naquela época um jogo desigual: uma enorme euforia motivada pelos ganhos com a economia extrativa e uma imensa penúria e carestia dos produtos de subsistência.

A carestia dos alimentos bem como sua escassez, fizeram com que regras e legislações fossem criadas pela Coroa portuguesa e depois pelo Governo Imperial no intuito de se garantir à população a oferta de alimentos em quantidade e preço justo, evidenciando-se a preocupação em relação à subsistência, um tema de abrangência social.

O mate fez com que a Província do Paraná se enquadrasse nos movimentos capitalistas da Economia-Mundo, mesmo que no contexto de uma nação periférica como o Brasil no que dizia respeito aos movimentos comerciais internacionais. Em suma, como relata Santos $^{11}$, tal situação levou à formação de uma estrutura neocolonial, integrada ao processo internacional de acumulação de capital, com as variáveis "terra" e "trabalho" levadas à linha do liberalismo econômico, mas adaptadas a condições próprias.

Os anos 1850 anunciaram, pois, mudanças estruturais na sociedade brasileira, principalmente a partir da inserção do Brasil na Economia-Mundo, da abolição do tráfico de escravos e da 
promulgação da Lei de Terras (Lei 601, de 18 de setembro de 1850) e a Província do Paraná não demoraria a sofrer a extensão dessas condições.

Mesmo com as novas regulamentações e os impactos internacionais sobre a produção e a venda de produtos paranaenses, a crise do setor agrícola continuava se constituindo em um foco permanente de carestia, apesar de toda a emancipação econômica e política promovida pela extração da erva-mate, influenciando todo o sistema de preços e a situação precária da subsistência no Paraná, que reproduzia a situação nacional.

Em 1870, enquanto a economia do mate seguia em alta nos quadros de exportação paranaenses, assistia-se ao declínio da economia pecuária, motivado pelo uso dos campos, antes utilizados somente para criação de gado, para as invernadas que se iniciaram em 1860, ou seja, para repouso e engorda do gado.

Com a crise da pecuária avolumada a partir de 1870, evidenciou-se uma “(...) nova forma de utilização da propriedade fundiária, reflexo da desagregação do sistema econômico-social estabelecido" sobre esta economia ${ }^{12}$. Diversas famílias de fazendeiros deixaram o campo e passaram a morar nas cidades, movimentando ainda mais o comércio urbano. Da mesma forma, o trabalho escravo, que anteriormente representava o alicerce da sociedade campeira, começou a sofrer reduções. Terras antes utilizadas na criação do gado e plantio de alimentos de subsistência passaram a ser utilizadas para as invernadas, que aparentemente geravam retornos mais fáceis e garantidos aos proprietários rurais. A terra passou a ser um bem de alto valor e elemento essencial da riqueza dos criadores.

Conforme corrobora Graham ${ }^{13}$, “(...) nenhuma cidade alimenta a si mesma". O abastecimento das cidades depende de um contingente de trabalhadores para plantar ou cultivar os alimentos, gente para transportá-los, intermediários para comprá-los e revendêlos aos consumidores. Sem o cultivo não há alimentos e sem os alimentos não há comércio. Sem comércio, não há a aquisição e a alimentação. Quando a oferta é pequena, quem tem condições de 
vender, o faz de forma especulativa e, assim, quem sofre as reais consequências é a população, que paga valores muito altos para ter acesso ao alimento. A carestia se consolida e prejudica ainda mais o consumo.

Em virtude das mudanças da sociedade desencadeadas pela desagregação da economia da pecuária, crises cíclicas internacionais que atingiam a economia do mate provocando queda de preços e a situação pífia da produção agroalimentar e de abastecimento na província, mesmo que algum excedente continuasse sendo comercializado para outras regiões do país, a província do Paraná viuse na emergência de construir um projeto de modernização e desenvolvimento da região, em termos sociais, econômicos e políticos. Como os movimentos escravistas foram sendo abolidos ao longo do tempo, o Paraná passou a ver com bons olhos a presença de trabalhadores imigrantes. Com a Lei de Terras de 1850 já em vigor, que instituiu a terra como mercadoria, estimulou-se a vinda dessas pessoas para prover a grande e a pequena lavoura com a mão-de-obra necessária, como parte de uma política colonizadora regional apoiada pelo Governo Imperial, em consonância com a política de emancipação.

Infelizmente, a política nacional de colonização, que utilizava mão de obra de imigrantes, foi direcionada inicialmente para atender as grandes lavouras, agora sem trabalho escravo. Mas, “(...) em relação à economia de subsistência, os liberais no poder acabavam por não reconhecer a existência de crise por falta de alimentos à população" $" 14$ e, por isso, as políticas de abastecimento continuavam a ser desenvolvidas e praticadas de forma regional, localizada, com foco em problemas específicos.

Na Província do Paraná, as ações e discursos dos presidentes buscavam recuperar a produção de alimentos a partir do trabalho livre e estabelecer políticas de abastecimento, implementando um processo de colonização que corroborasse com um projeto de modernização e desenvolvimento regional.

Inicialmente, a vinda dos imigrantes não surtiu o efeito esperado pelo governo provincial na produção de alimentos, uma vez

14 SANTOS, op.cit.,p.66. 
que não houve comprometimento do Governo Imperial com a empreitada. Mesmo com a presença de imigrantes, o liberalismo econômico tentava manter a ideia de que a vocação agrícola do país era produzir para exportar, sem a preocupação com a produção de alimentos para atender as necessidades da população local.

Em 6 de abril de 1876, o então presidente da Província do Paraná, Lamenha Lins, promulgou a Lei 451, estabelecendo grupos de estudos sobre imigração a fim de fixar os imigrantes em colônias nos arredores dos centros urbanos. Com sucesso, a experiência pioneira desta fixação se deu com a Colônia de Santa Cândida, e a partir daí outras colônias foram fundadas, tais como as de Órleans, D. Pedro, D. Augusto, Tomás Coelho, Lamenha, Santo Inácio e Riviére, ao redor de grandes cidades como Curitiba ${ }^{15}$.

Ainda em 1876 o governo Lamenha Lins já havia estabelecido 12 colônias nos arredores de Curitiba e uma série de ações relacionadas ao novo plano de colonização agrícola foram colocadas em prática, visando suprir os centros urbanos por meio da agricultura de subsistência e a garantia do abastecimento. Assim, as colônias passaram a produzir milho, arroz, feijão, mandioca, verduras, frutas e a criar animais domésticos, cujos excedentes eram comercializados em Curitiba. Passaram a alimentar as cidades e a oferecer um certo suporte ao setor de exportação, pois alguns gêneros paranaenses, via sistema de cabotagem, atingiram outras praças nacionais, em valores apreciáveis comparados com as exportações anteriores.

A experiência profissional trazida pelo camponês europeu no trato da terra e na introdução de novos meios de trabalho deveria ser passada ao camponês brasileiro, acostumado ao uso de métodos rudimentares, depredatórios e exploratórios como a queimada e a roçada. Melhorar a técnica de preparo poderia, entre outros fatores, aumentar a produtividade das terras.

Nas colônias estabelecidas ao redor de Curitiba, produzia-se centeio em grande escala, trigo, batata, milho, feijão, ervilha, fumo e legumes em geral, dependendo da etnia dos imigrantes de cada uma das colônias. Algumas colônias, menos produtivas, forneciam lenha

15 SANTOS, op.cit.,p.75. 
para a Capital. Outras, localizadas mais ao litoral da Província, produziam cana-de-açúcar, café, vinho, mandioca, fumo, arroz, milho, araruta e feijão.

$* * *$

3. "Ao se analisar a formação de um sistema de produção agroalimentar deve ser considerado que este conjunto se refere às atividades que definem a função 'alimentação' numa dada sociedade"16 . Quando Santos escreveu esta frase em História da alimentação no Paraná, certamente estava se referindo ao fato de que toda a cadeia de produção de alimentos está atrelada não apenas à sua produção, mas à sua industrialização ou ao seu beneficiamento, comercialização e distribuição. Sem estas etapas da cadeia de produção de alimentos, não se gera o consumo. Todo este conjunto denominado produção agroalimentar está inserido em uma formação econômica e social, dependendo diretamente de sua estrutura e organização. A produção agroalimentar exprime a visão da sociedade em que está inserida, é afetada por suas dinâmicas e afeta diretamente o consumo alimentar das populações envolvidas e, assim, seus hábitos alimentares. O que está sendo produzido e ofertado é o que passa a ser consumido pela população e inserido como parte de seus hábitos alimentares.

Na Província do Paraná, as novas condições de hábitos e de consumos alimentares implicaram maior capacidade de produção agrícola, diversificação dos produtos, meios de transporte alternativos e implantação de redes viárias, novos mercados e patamares do sistema agroalimentar.

Santos ${ }^{17}$ evidencia que, durante o século XIX, produtos como milho, feijão, arroz, farinha de mandioca, carne verde, trigo, centeio e mate eram considerados básicos para o regime alimentar da 
população, pois se encontram na maioria das fontes pesquisadas. Mesmo que a carne fosse muito desejada e recomendada devido às suas características nutricionais, não era acessível à grande parte da população, em virtude de seus preços elevados.

Produzido em boa parte da região, tanto no período da Comarca como da Província do Paraná, o feijão constituía produto básico da lavoura de subsistência, compondo, juntamente com o milho e a mandioca, a dieta da maior parte dos produtores e da população de baixa renda presente nas cidades.

$\operatorname{Santos}^{18}$ afirma que o feijão era um dos produtos mais enfatizados em relatórios da economia paranaense, em que se mencionava a importância e a presença desse alimento na refeição de trabalhadores contratados por jornada de trabalho, juntamente com farinha e charque. $\mathrm{O}$ autor relata, ainda, que o feijão, um dos produtos que mais se adequava à terra paranaense, sempre foi cultivado para consumo, mesmo em momentos de escassez, sendo o feijão preto muito referenciado em anúncios ao longo do século XIX.

$\mathrm{O}$ autor também cita que o milho, juntamente com o feijão, a farinha de mandioca e o charque, era considerado gênero de primeira necessidade para a alimentação da população. Da mesma forma que o feijão, a produção de milho estendeu-se ao longo do século XIX em todas as áreas de produção agrícola do Paraná. Considerada como área de boa produção para este alimento, a Província era estimulada ao seu plantio, mesmo que a derrubada e a queimada se constituíssem base preliminar para este cultivo. Sérios problemas de oferta deste alimento ocorreram ao longo do século XIX, gerando descontentamento da população e carestia.

Dentre os alimentos mais produzidos e consumidos no Brasil ao longo de toda a sua história está a mandioca. Descrita como o "pão da terra" pelos navegantes e colonizadores, a mandioca tornou-se alimento básico da alimentação da população brasileira, por ser um produto de produção e consumo doméstico.

No Paraná, a mandioca tornou-se produto típico do litoral, apesar de também ser produzida em menor escala em outras regiões. No século XVIII, a farinha de mandioca era largamente produzida no

18 SANTOS, op.cit. 
litoral, exportada pelo porto de Paranaguá e vendida em Curitiba, tornando-se amplamente consumida por ricos e pobres e integrada aos hábitos alimentares dos habitantes da região. Versátil para uso em diversas preparações, a farinha de mandioca passou a integrar a mesa do paranaense e se tornou ingrediente de iguarias bem conhecidas da nessa cozinha paranaense.

O arroz, no Paraná, era até a década de 1860 um produto complementar, que não fazia parte da lista de gêneros de primeira necessidade, com exceção de algumas regiões da Província. Foi a partir de 1870 que passou a ser percebido como gênero básico, sendo incluído nas listas de comercialização e controle de especulações comerciais.

De acordo com Santos ${ }^{19}$, a carne verde figurava entre os gêneros alimentícios inseridos em processos de crise constante: preços elevados, qualidade do produto, aspectos de higiene, divergências entre os comerciantes e a população, manipulação de pesos, entre outros. Ainda, o universo da carne verde envolvia interesses diversos de produtores, comerciantes, governos e populações em face do capital comercial em expansão, “(...) a ponto de se poder afirmar, sem grande exagero, que a história do abastecimento no Brasil é, sobretudo, a história da carne verde" ${ }^{\text {20 }}$.

No Paraná, ao longo do século XIX, a carne verde não era considerada como gênero de primeira necessidade, ainda que houvesse demanda por parte da população pelo controle de preços. Parte da dificuldade de negociá-la, em todas as regiões paranaenses, devia-se à falta de qualidade do produto, asseio dos estabelecimentos e oportunidade de preço acessível.

Para Santos ${ }^{21}$, “(...) os cereais tiveram um peso considerável sobre a população camponesa e a vida global dos homens", sendo que o trigo, juntamente com cereais secundários como a cevada, a aveia e o centeio, afirmou a expansão da civilização europeia. No Brasil, mesmo diante de culturas rivais como o milho e a mandioca,

19 SANTOS, op.cit.

20 SANTOS, op.cit.,p.131.

21 SANTOS, op.cit.,p.137. 
estabeleceu-se como gênero essencial a partir da colonização dos imigrantes, já que fazia parte de seu hábito alimentar.

$\mathrm{Na}$ primeira metade do século XIX, embora já existisse alguma produção na Província do Paraná, o trigo era essencialmente importado para atender a demanda da população. E em meados do século, contrariamente, já se viam produções significativas de um trigo considerado de boa qualidade em algumas áreas paranaenses, que posteriormente foram praticamente devastadas pelas pragas inerentes à esta cultura, fazendo com que a Província e o restante do país gastassem valores razoáveis na importação do produto.

Em 1857, o parlamento votou a Lei 939, com o objetivo de estimular a retomada da produção de trigo no país e, assim, atrair a mão-de-obra imigrante, cujo principal alimento de consumo era o pão. Assim, é possível evidenciar, por meio da obra de Santos, a criação de uma política pública de compra de sementes de trigo a fim de garantir aos consumidores do grão que eles poderiam manter seus hábitos alimentares nesta nova terra.

Com esta política de incentivo à produção de trigo, houve estímulo e apoio às várias fases da cadeia de produção como, por exemplo, melhorias nas sementes, nos métodos de cultivo e de beneficiamento, no escoamento da produção, expansão de padarias (emergindo o estrangeiro no ofício de padeiro) e inserção de novas técnicas de preparo do pão - fazendo dele um alimento indispensável à população.

A expansão do comércio de pão na Capital deveu-se, em grande medida, à vinda dos imigrantes europeus para o Paraná e sua fixação em colônias agrícolas nos arredores de Curitiba. Como o preço do pão branco, feito somente de trigo, era elevado, ele era consumido apenas pelos ricos. Aos pobres restavam os pães cujo trigo era misturado com algum outro tipo de cereal, chamados de broa, introduzindo-se o hábito na população paranaense de utilizar centeio e cereais diversos.

O mate foi, conforme afirmação de $\operatorname{Santos}^{22}$ já mencionada, uma das mercadorias mais produzidas e exportadas pelo Paraná no século XIX. Sofrendo reflexos diretos da economia internacional,

22 SANTOS, op.cit. 
teve oscilações em sua produção e importância, mas não deixou de ser foco principal da produção dos grandes latifúndios agrícolas no período. Santos relata que a erva-mate era a bebida mais popular, por ser mais barata que o café, o chá verde e o chá preto. No Paraná de 1885, a ingestão do mate feito na base do chimarrão era bastante significativo - conforme Santos, o consumo per capita era de três cuias por dia. Além da influência decisiva do mate na economia da Comarca e da Província, o produto também fazia parte dos gêneros básicos para o abastecimento doméstico, juntamente com o feijão, a mandioca, o milho, o arroz, a carne e o trigo. Outros itens como o charque, o açúcar, o sal e cereais complementares como o centeio, a cevada e a aveia também tiveram grande importância na dieta paranaense ao longo do século XIX.

$\operatorname{Santos}^{23}$ reforça, ainda, que “(...) qualquer inventário sobre a produção agroalimentar no Brasil deve levar em consideração que três variáveis estiveram aí permanentemente presentes: a escassez, a carestia e a qualidade dos alimentos". A presença constante destas três variáveis definiu o nível de oferta, as possibilidades e dimensões de acesso por parte da população de baixa renda aos gêneros de primeira necessidade e a qualidade dos produtos disponíveis.

A escassez dos alimentos gerava a exploração pelos mercados e a carestia dos alimentos, tornando-se um grave problema para o acesso a eles de boa parte da população paranaense e uma grande preocupação das autoridades. No intuito de resolver a situação e tornar mais justa a aquisição dos alimentos, foram promulgadas leis, resoluções, posturas e outros ordenamentos jurídicos. A carestia dos produtos de consumo alimentar se evidenciou ao longo de todo o século XIX, gerada pelos maus sistemas produtivos, pela ação de intempéries e das pragas, pela falta de mão de obra para a produção, pela deficiência no modal de distribuição, pela falta de estruturas comerciais adequadas nos centros urbanos, pela especulação dos comerciantes e atravessadores, pelos altos custos com a importação de alimentos e pela escassez de técnicas de melhoria da produtividade da terra.

23 SANTOS, op.cit.,p151. 
No tocante aos estudos realizados por este autor sobre o cotidiano dos alimentos no Paraná, constata-se um quadro de face dupla, que evidencia a formação de uma estrutura agroalimentar com políticas de abastecimento e projeto de modernidade na colonização e produção de gêneros.

4. A presença constante da trilogia escassez, carestia e qualidade tem implicado crises de abastecimento de gêneros alimentícios, principalmente para as populações mais pobres, no país como um todo, desde os movimentos de colonização.

A agricultura de subsistência tem sido essencial para gerar economia, seja porque gera produtividade, seja porque seus excedentes podem ser comercializados. Entretanto, até os dias atuais, tais movimentos ainda não são adequadamente valorizados por boa parte dos governos do mundo, que os mantêm à margem, discriminados e sem incentivos.

Assim como Santos $^{24}$ (2007) evidenciou a escassez e a carestia de produtos alimentícios no Paraná do século XIX, observase que atualmente muitos países já não possuem nem reservas satisfatórias de alimentos, nem capacidade de produzi-los. Dependem da importação de alimentos e das constantes oscilações dos valores de mercado, o que gera carestia e dificuldades na aquisição dos alimentos por parte da população ${ }^{25}$. Os problemas evidenciados há mais de um século parecem se repetir nos movimentos atuais de produção de alimentos.

24 SANTOS, op.cit.

25 MENDONÇA, Maria Luísa; ROSSET, Peter. Agrocombustíveis e crise dos alimentos. Revista do Observatório das Nacionalidades, v. 5, n. 8, jan./jul., 2009. Disponível em: https://www.academia.edu/2891348/Agrocombust\%C3\%ADveis_e_crise_de_alimentos Acesso em: 09 de set. 2016.p.215. 
As aflições permanentes dos agricultores, desde os séculos XVIII e XIX, revelam a necessidade de melhores condições de trabalho que lhes assegurem a manutenção de suas conquistas. Ações de capacitação técnica, tanto no campo quanto para estratégias de venda, ainda são latentes e necessitam de apoio para seu desenvolvimento e sustentabilidade, tanto das próprias organizações das famílias agricultoras como do Estado, compartilhando assim as responsabilidades na produção e abastecimento das populações.

Conhecido atualmente como celeiro agrícola do Brasil, o Paraná tem enfrentado, desde sua colonização, diversos movimentos e crises relacionados ao abastecimento que impactam de forma direta seu desenvolvimento econômico e social. O desabastecimento de alimentos de subsistência gerada pela produção em massa de alimentos para a exportação, percebida de forma atenta no século XIX com a erva-mate e arroz, continua sendo alvo de inúmeros questionamentos de todos os que buscam o equilíbrio da segurança alimentar e nutricional, já que interfere no direito humano à alimentação. Se antes era a carne, o mate, o arroz, hoje são os produtos agrícolas transformados em commodities, regulados pelas regras de mercado, que colocam em risco o abastecimento alimentar das populações, além da diversidade alimentar dos povos e a preservação da biodiversidade.

Deixar de produzir para subsistência com foco na produção de larga escala continua sendo um dos fatores de crise no abastecimento. Dar maior apoio financeiro aos grandes latifúndios, subjugando os pequenos produtores, tem sido um dos grandes geradores de desigualdades sociais e de escassez de alimentos e recursos por boa parte da população. Produzir sem apoio tecnológico e sem a garantia da desova da produção faz com que muitos pequenos produtores abandonem suas propriedades e produções, aumentando os percentuais de migrantes nas grandes cidades e prejudicando ainda mais o abastecimento. Os contextos de mercantilização e externalização da agricultura fazem com que a produção para o autoconsumo continue sendo largamente afetada. Estimuladas a produzir mormente produtos comerciais, visíveis e sancionados pelo mercado, as unidades familiares acabam por reduzir o tempo e o 
espaço para a produção de alimentos para seu próprio consumo, invisível aos olhos do mercado ${ }^{26}$.

O ciclo retratado por Santos ${ }^{27}$ vem se repetindo nos séculos posteriores à sua análise historiográfica. Nós críticos que, no século XIX, provocavam sérios problemas no abastecimento de gêneros agrícolas repetem-se ainda hoje como, por exemplo, as técnicas rudimentares, a falta de tecnologia e apoio à produção, a falta de mão de obra produtiva, a falta de acessos viários e a competitividade de produção com produtos mercadologicamente mais rentáveis que geravam escassez dos alimentos de primeira necessidade.

A determinação sobre o que se produz e quando se produz definida pela Economia-Mundo no século XIX parece ter se repetido posteriormente nos sistemas capitalistas, nos quais os países que dominam as relações econômicas no contexto internacional movimentam a produção e o consumo de alimentos global de acordo com seus interesses políticos e econômicos. "Sob a forma de agronegócio as atividades agropecuárias vêm sendo cada vez mais controladas por conglomerados econômicos que atuam em escala mundial determinando o que, quanto, como e onde devem ser produzidos e comercializados os produtos de origem vegetal e animal" $^{\prime 28}$.

Campos e Campos (2007) também declaram que o agronegócio nada mais é do que uma nova forma de territorialização do capital no campo, forjada em um contexto de políticas neoliberais e de intensificação dos processos de concentração e centralização do capital em múltiplas escalas, especialmente mundial. Uma versão mais contemporânea do que já ocorria no século XIX, por determinação nacional ou da Província do Paraná.

$\mathrm{O}$ acesso à alimentação adequada deveria ser consequência de um sistema alimentar sustentável, que protegesse e respeitasse o ambiente natural de onde os alimentos são obtidos. Entretanto, a

26 GRISA, C. Para além da alimentação: papéis e significados da produção para autoconsumo na agricultura familiar. Revista Extensão Rural. 2007; XIV:5-35.p.7.

27 SANTOS, op.cit.

28 CAMPOS, Christiane Senhorinha Soares; CAMPOS, Rosana Soares. Soberania alimentar como alternativa ao agronegócio no Brasil. Revista Electrónica de Geografía y Ciencias Sociales [Internet]. 2007; 11(245). Disponível em: http://www.ub.edu/geocrit/sn/sn-24568.htm. s/p 
evolução recente dos sistemas alimentares, na maior parte do mundo, tem indicado convergências para um sistema altamente industrializado, globalizado e dominado por poucos agentes econômicos, com características que impactam desmedidamente na sustentabilidade dos sistemas, não convergindo com produções pequenas e de subsistência ${ }^{29}$ (CONTRERAS; GRACIA, 2011).

Paradoxalmente, desde que as sociedades se reconhecem como tais, muitos países cujas populações passam fome, seja pela baixa disponibilidade de alimentos ou por escassos recursos financeiros para sua aquisição, são também grandes produtores de alimentos para o mercado internacional. Assim, em detrimento do abastecimento de suas populações, suas produções acabam alimentando os países desenvolvidos do mundo - fato ainda muito percebido no território brasileiro e no Paraná. Por isso, a história da fome no mundo parece estar ligada, de forma direta ou indireta, à sociedade da abundância e do consumo (CONTRERAS; GRACIA, 2011).

São relações de poder que interferem diretamente na produção, distribuição e consumo de alimentos no mundo. Como demonstram Campos e Campos ${ }^{30}$, o avanço do agronegócio não ocorre de maneira harmônica, já que seu desenvolvimento é pautado por muitos paradoxos, entre os quais o aumento da insegurança alimentar e da desigualdade social, dos conflitos no campo e da destruição ambiental.

Segundo o Conselho Nacional de Segurança Alimentar e Nutricional (2007), “(...) o acesso à alimentação é um direito humano em si mesmo, na medida em que a alimentação constitui-se no próprio direito à vida. Negar este direito é, antes de mais nada, negar a primeira condição para a cidadania, que é a própria vida"31. Portanto, quando não se possibilita à população o acesso ao alimento, seja pela sua inexistência, pela sua qualidade ou pelos valores

29 CONTRERAS, Jesús; GRACIA, Mabel. Alimentação, sociedade e cultura. Rio de Janeiro: Editora Fiocruz, 2011. 496 p.

30 CAMPOS, op.cit. s/p.

31 BRASIL. Conselho Nacional de Segurança Alimentar e Nutricional. Por um desenvolvimento sustentável com soberania e segurança alimentar e nutricional. Relatório da III Conferência Nacional de SAN. Fortaleza: Consea, 2007. Disponível em: https://www.planalto.gov.br/consea 
financeiros para sua aquisição, não se está assegurando o mais básico de todos os direitos.

No século XIX, a escassez, a carestia e a baixa qualidade dos alimentos eram responsáveis pela fome da população e, como consequência, havia baixa produção agrícola e, portanto, mais escassez, carestia e baixa qualidade. Produzia-se, assim, um ciclo de insegurança alimentar e nutricional e uma ruptura da soberania alimentar da população.

Mesmo que se perceba no plano de modernização da produção de alimentos implementada pelo Presidente Lamenha Lins, na Província do Paraná, pela colonização por imigrantes, o desejo de atender a demanda de alimentos em cada região, com base no respeito à cultura alimentar de cada grupo e etnia, não se pode confirmar que seu interesse primário era o de garantir a soberania alimentar do paranaense. Comer representava garantia de trabalho e geração de receitas e, dessa forma, reestruturar os mercados locais, para a partir deles combater a crise alimentar, possivelmente só almejava a garantia de mercados e do crescimento econômico da Província.

Portanto, não há o que se questionar: o debate acerca das dimensões da cadeia agroalimentar, produção e consumo, não ocorre há pouco tempo no Brasil. Tem raízes plantadas em nossa história, que se repete, com seus erros, problemas e interesses econômicos.

\section{Considerações Finais}

O fio condutor da análise que a História da alimentação no Paraná propõe é o da colonização agrícola, da produção dos alimentos e do abastecimento na segunda metade do século XIX no Paraná como elementos aglutinadores de outras categorias socioeconômicas, tais como o mercado interno, produtos de subsistência, preços, qualidade, carestia e penúria. Entretanto, tal obra trata de um assunto que transcende a época temporal retratada, pois discute situações que são rotineiras ainda hoje. 
Ao se verificar as formas de apropriação e utilização das terras produtivas hoje, analisar os incentivos e objetivos propostos pelo mercado, evidencia-se que os interesses políticos e econômicos continuam falando mais alto do que a subsistência da população, o acesso a alimentos limpos e seguros, a segurança e a soberania alimentar.

Outra importante referência dos estudos de $\operatorname{Santos}^{32}$ é à formação dos hábitos alimentares, gerada e movimentada pela disponibilidade dos alimentos, ou seja, come-se o que se tem para comer, compartilha-se o que se tem para compartilhar e se inclui no gosto e na cultura alimentar aquilo que se tem acesso.

Para o autor, seja na sua obra História da alimentação no Paraná, seja nas inúmeras contribuições teóricas deixadas por ele, comer é um ato social atrelado a atitudes, usos, costumes, protocolos, condutas e situações, sendo espelho e reflexo das diferentes épocas e sociedades, o que remete à importância de se correlacionar o universo da agricultura de subsistência, o alimento e o comer. Não se pode perceber o hábito sem o acesso ao alimento, não se pode perceber a cultura alimentar sem a disponibilidade e a utilização dos alimentos nos tempos, nas regiões, na terra e nas panelas.

Sejam frutos da produção doméstica, de subsistência ou de largas e vastas produções, os alimentos transitam e constituem consumos. São inseridos na alimentação dos indivíduos e das famílias e produzem hábitos, repassados de geração em geração.

No Paraná do século XIX, poucos gêneros faziam parte do consumo alimentar, uns trazidos e incorporados, outros regionais. Milho, feijão e mandioca foram traduzidos como a base da alimentação do paranaense, da gente pobre e trabalhadora. Os mesmos milho, feijão e mandioca plantados em diferentes áreas da antiga Província do Paraná passaram a incorporar o hábito alimentar do paranaense do litoral, do primeiro e do segundo planalto. Terra boa para o plantio do feijão, o Paraná expandiu sua produção ao longo dos séculos e acabou por se tornar um grande celeiro deste alimento, sendo até hoje reconhecido como uma das regiões brasileiras que mais o produz. Terra boa para o plantio da erva-mate, o estado fez de 
seus territórios um jardim verde de produção e incorporou nos filhos de sua terra o hábito de beber o tal chimarrão. Terra boa para o plantio da mandioca, o litoral do Paraná passou a produzi-la em larga escala no século XIX e a exportar farinha para outras regiões do país - que hoje utiliza tal produto como uma das bases de sua gastronomia, principalmente a litorânea. $\mathrm{O}$ milho, que era alimento indígena, caiu no gosto dos portugueses e africanos desde o início da colonização e continuou sendo alimento básico à alimentação de todos, sob as mais diversas formas de consumo.

Se milho, arroz e feijão eram os alimentos básicos da vida humana, o milho foi fundamental também para a criação de suínos e para a obtenção do toucinho, seu mais importante subproduto, que era usado para cozinhar, untar e preservar os alimentos, conforme cita Luna e Klein ${ }^{33}$. Assim como no Paraná, os alimentos básicos como milho, arroz, feijão e carnes foram, desde os primeiros tempos, produzidos em todas as partes de São Paulo, tanto no litoral como no planalto, fazendo parte do consumo de sua população ${ }^{34}$.

Hábitos construídos ao longo do tempo e que só puderam se efetivar pela permanência da produção e acesso destes alimentos à mesa da população. Ao se analisar alguns comportamentos alimentares da região interiorana do atual Estado do Paraná, verificase a presença do arroz, do feijão, da carne de porco, da carne verde e da mandioca cozida como bases da alimentação da maior parte das famílias, dia após dia. Produzir arroz, além de ter como foco a economia e o aumento de divisas, incorporou na população paranaense o hábito de seu consumo.

Alguns autores, tais como Scarano (1990/1991), ainda referenciam que o padrão alimentar dos homens livres ou escravos ao longo da colonização e dos séculos posteriores não se diferenciava daquele que havia no Brasil do século XVIII, formado por farinha de mandioca ou de milho feita com água e mais alguns complementos. A mandioca de tipo americano substituiu o inhame africano e o milho substituiu o milharete, fazendo com que estes dois alimentos,

33 LUNA, Francisco Vidal Luna; KLEIN, Herbert S. Klein.. Escravidão africana na produção de alimentos. São Paulo no século 19. Estud. Econ., v.40, n.2. São Paulo, jun./2010.

34 BARBOSA, Lívia. Feijão com arroz e arroz com feijão: o Brasil no prato dos brasileiros. Horizontes Antropológicos, Porto Alegre, ano 13, n. 28, p. 87-116, jul./dez. 2007. 
associados ao feijão, passassem a ser os mais utilizados na alimentação destas populações.

Em estudo realizado por Barbosa ${ }^{35}$, nota-se que a trilogia arroz, feijão e carne tem, em comparação com outros alimentos, o maior consumo diário na maior parte das regiões brasileiras, incluindo a paranaense, até os dias de hoje, mesmo diante de uma nova realidade social e de alimentação. Também são consumidos constantemente a farinha de mandioca e o milho, ambos componentes de inúmeros preparações.

Conforme referencia Montanari ${ }^{36}$ (2008), cada região do mundo acabou por eleger seu cereal preferido: o trigo, tão difundido nas regiões mediterrâneas e por todos os seus descendentes; o sorgo no continente africano; o arroz na Ásia; e, o milho na América. Cultivados desde os primórdios das civilizações humanas, estes cereais tornaram-se "verdadeiras plantas de civilização" que, disponíveis ou introduzidas, circularam ao redor do mundo e passaram a compor a alimentação do brasileiro, incluindo o paranaense.

Com a colonização estimulada pela Lei de Terras, a região Sul do Brasil recebeu grande contingente de imigrantes europeus, que introduziram em terras paranaenses novos consumos e hábitos, novos gostos e sabores. Podemos observar com o aval de Santos, que as cozinhas locais, regionais, nacionais e internacionais são produtos da miscigenação cultural, estabelecem trocas culturais por meio das diferentes culinárias, evidenciando que o gosto alimentar não se dá exclusivamente pelos seus aspectos biológicos e nutricionais, mas constitui-se como uma categoria histórica e cultural.

RECEBIDO EM: 16/03/2017 APROVADO EM: 17/05/2017

35 BARBOSA, op.cit.

36 MONTANARI, Massimo. Comida como cultura. São Paulo: Editora Senac São Paulo, 2008.p.24. 